\title{
VULNERABILITY ASSESSMENT OF ITALIAN RATIONALIST ARCHITECTURE: TWO CASE STUDIES
}

\author{
P. BERNARDI ${ }^{1}$, R. CERIONI $^{1}$, E. COÏSSON $^{1}$ AND E. MICHELINI $^{1 *}$ \\ ${ }^{1}$ Department of Engineering and Architecture \\ University of Parma \\ Parco Area delle Scienze 181/A, 43124 Parma, Italy \\ e-mail: \{patrizia.bernardi, roberto.cerioni, eva.coisson, elena.michelini\}@ unipr.it, https://dia.unipr.it \\ (*corresponding author)
}

Keywords: Masonry Buildings, Knowledge Process, In Situ Surveys, Static and Seismic Assessment, Rationalist Architecture

\begin{abstract}
The work is focused on the structural vulnerability assessment of two historical constructions, chosen as case-studies representative of a recurrent typology of Italian rationalist architecture, dating back to the Fascist period, often hosting public offices. Both examined buildings have similar dimensions and geometry, being characterised by five/six storeys and by an almost square plan with an inner courtyard, and are located in EmiliaRomagna, in zones of medium seismic hazard. The older building, dating back to the Thirties and located in Ravenna, has a mixed masonry-reinforced concrete structure, while the other one, built in the late forties and located in Parma, is characterised by an unreinforced masonry structure with some limited reinforced concrete elements. For the vulnerability assessment of the two buildings, a multi-disciplinary approach was followed, including the historical documents search concerning both the investigated buildings and the surrounding areas, the detailed geometrical and structural survey, the identification of materials, and in situ and laboratory tests to evaluate materials mechanical properties. These activities allowed reaching an adequate level of knowledge about the present conditions of the structures and their critical deficiencies. This knowledge path is not only necessary for the subsequent numerical analyses, but is also important as it allows targeting the repairing interventions, possibly reducing their final costs, in agreement with the "minimum intervention" approach for heritage buildings.
\end{abstract}

\section{INTRODUCTION}

In Italy all public buildings older than 70 years are ope legis considered enlisted buildings, protected by the Ministry of Cultural heritage [1]. This normative prescription is producing more and more enlisted buildings every year, including lately also the period of post WWII. The buildings that have been added to the Superintendency lists in the last decades date back to a period in which the building typologies, the technical solutions, the materials features evolved very rapidly. International organizations like DOCOMOMO, ICOMOS, Getty 
Foundation and World Monument Fund are devoting attention and specific documents to the conservation of these newly defined monuments, but in Italy the Rationalist architecture, earlier subjected to a damnatio memoriae due to its Fascist commissioning, is getting only recently more attention and value recognition, which is at the base of a restoration-based approach [2]. Moreover, while the experience on analyzing and restoring older typical masonry structures is large, for these more recent constructions, knowledge is lacking and a correct approach to its analysis is still to be defined. Often these buildings are a mixture of masonry and concrete structures, but the details of reinforced concrete elements are different from todays' ones and - on the other side - bricks and mortars composing the masonry parts are different from traditional ones. In order to carry out a structural analysis on these modern structures, as for all existing buildings, surveys, inspections and on site tests are mandatory and should always take into account also non-structural elements, frequently underestimated in numerical analyses. Real safety comes from deep knowledge, rather than from advanced calculations. The empirical/experimental method developed in the end of the $20^{\text {th }}$ century for historical masonry buildings [3] should also be applied to these more recent and mixed structures, in order to identify the most probable and dangerous mechanisms. To this aim, the analysis of two case studies appears to be meaningful for a better definition of the correct study path.

\section{CRITICAL HISTORY ANAL YSIS AND DESCRIPTION OF THE BUILDINGS}

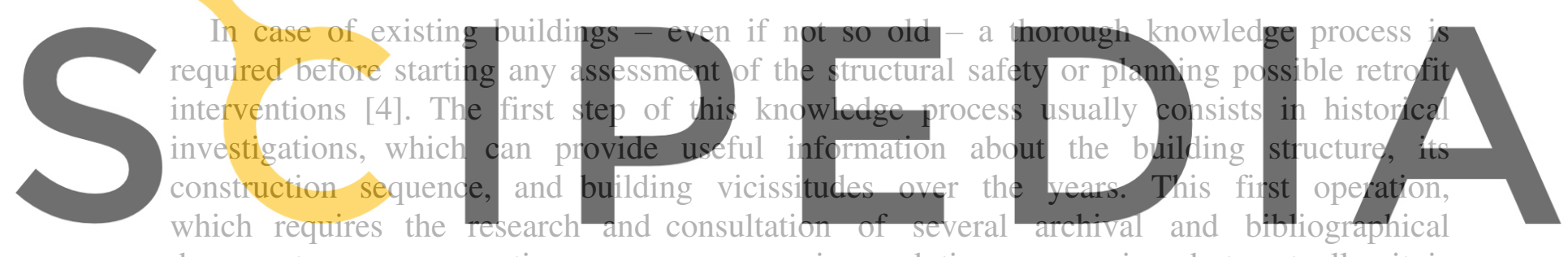

documents, may sometimes appear expensive and time consuming, but, actually, it is

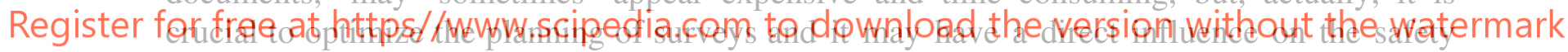

assessment of the building, influencing the modeling choices. Even in case of historical building belonging to an aggregate, the knowledge process is mandatory in order to identify correctly those structural units having a unitary response against seismic actions, as also suggested in [5-7].

\subsection{The "Ex-Magistrato per il Po e Genio Civile" building in Parma (Italy)}

The "Ex-Magistrato per il Po e Genio Civile" building, briefly named in the following as "MagisPo", is located in Parma and currently hosts public offices. The draft of the building dates back to the early second post-war period. Building works started in 1947 and lasted until 1959. The building was erected in an urban area - bombed during WWII - between the railway station and the main square of the town (Fig. 1a). The structure of the building and its geometrical configuration underwent some major changes during the construction works, so they do not correspond completely to the 1947 drawings, as can be seen in Figures 1b,c and 2a,b. These drawings show indeed the plans for three main separate buildings, arranged around a common inner courtyard (see Fig. 1b). As can be seen from Figure 1c, only the front building was instead erected, and its original U-shape was modified by connecting the two lateral wings with a rear façade (Figs. 1c and 3d), thus forming an internal closed court. 


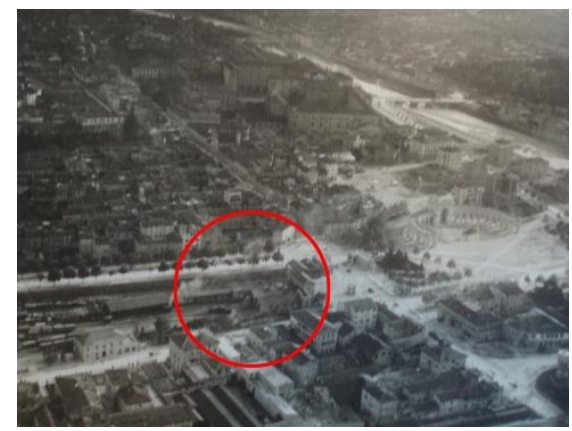

(a)

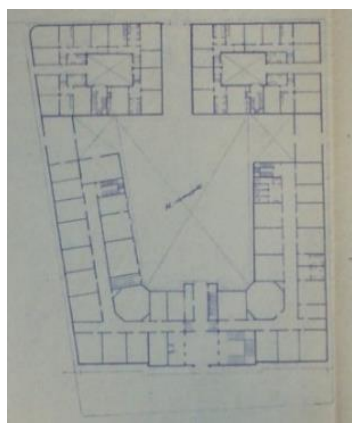

(b)

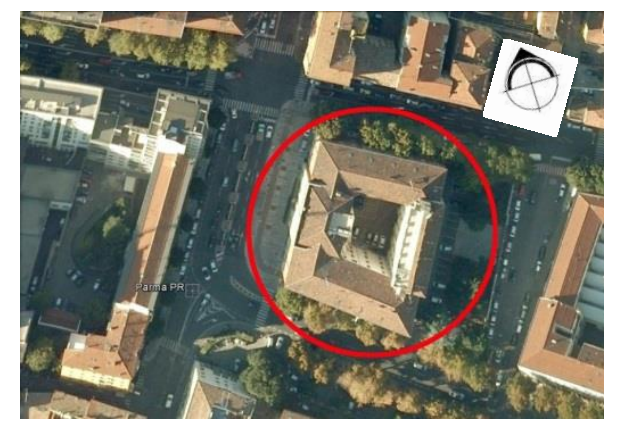

(c)

Figure 1: (a) Aerial view of Parma at the end of the $19^{\text {th }}$ century, with indication of the analyzed area; (b) plan of the building taken from the draft of 1947; (c) aerial view of the MagisPo building from a satellite

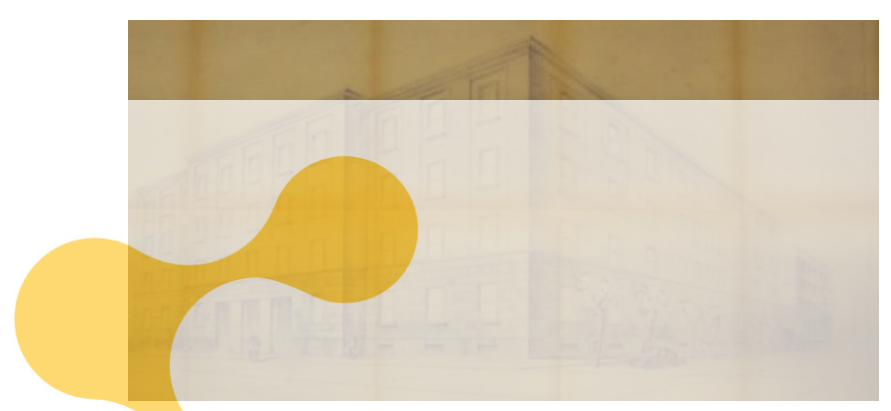

(a)
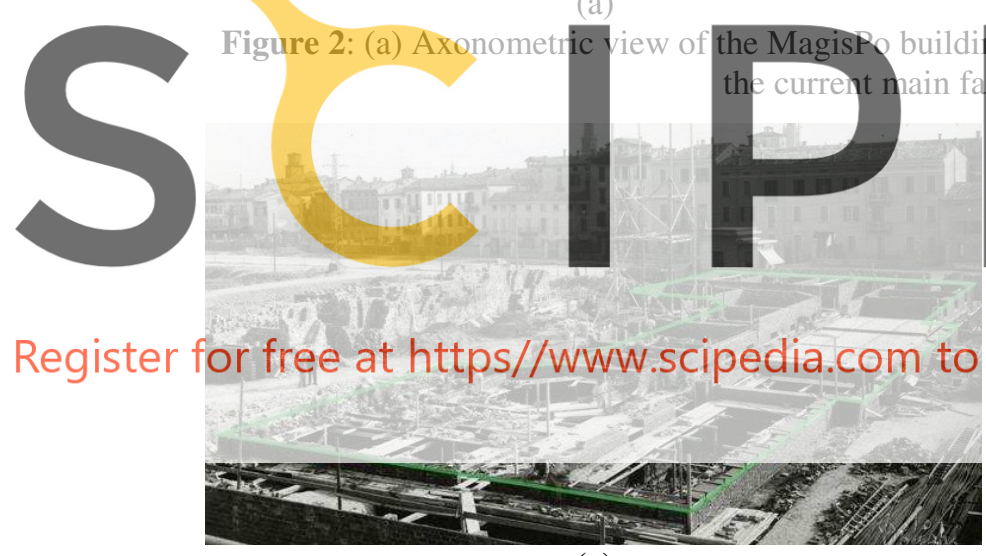

(a)

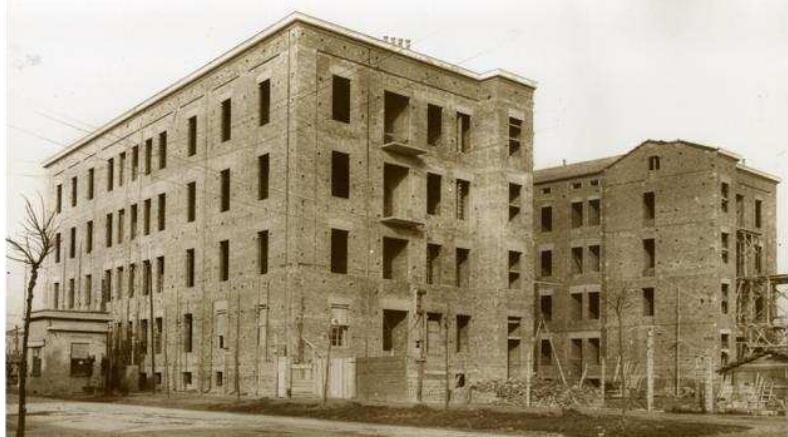

(c)

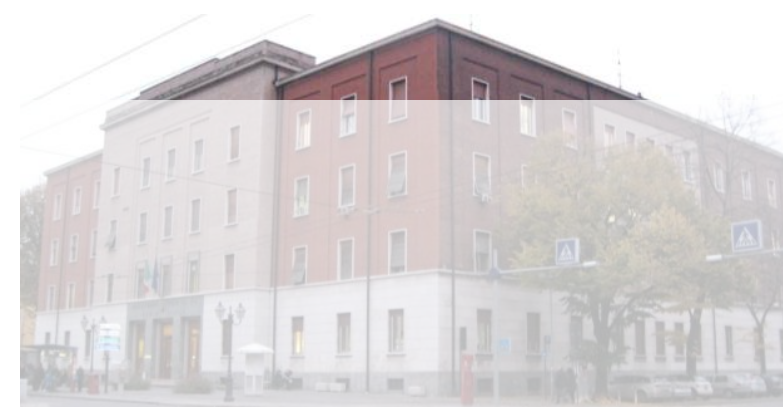

(b)
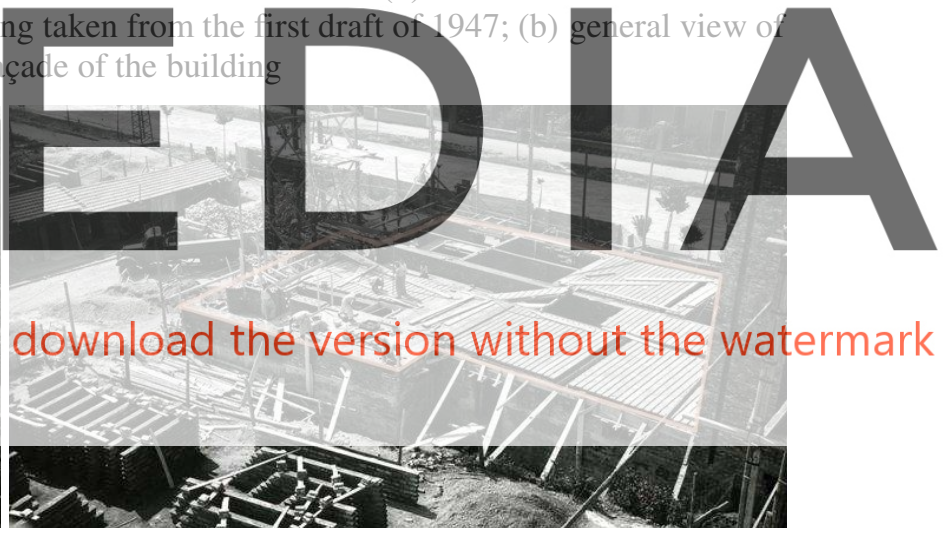

(b)

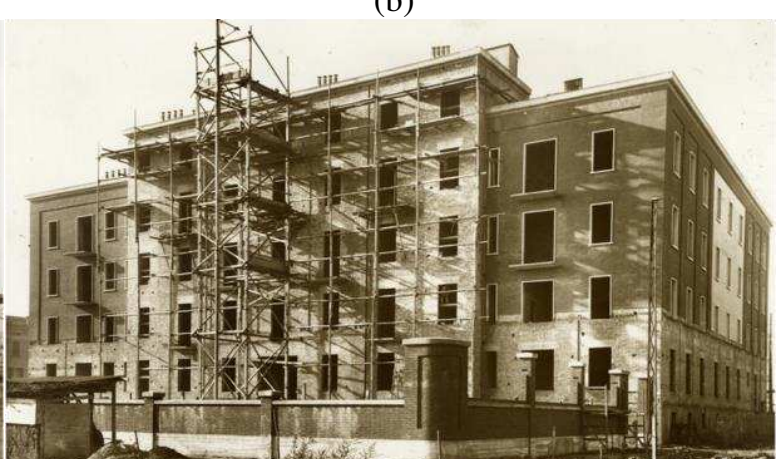

(d)

Figure 3: Historical photos documenting the construction stages of MagisPo: (a) erection of the main façade (1948); (b) erection of the east wing (1950); (c) view of the building at mid-Fifties (main façade and the two wings completed); (d) addition of the rear façade (1957) 
The construction of the building took place in four subsequent stages, as proved by the historical pictures taken during the works (Fig. 3). The plan was divided into three parts, each one completed before the erection of the next one: the main façade was realized first (Fig.3a), then the two lateral wings (Figs. 3b,c), and finally the rear façade was added (Fig. 3d). To join the adjacent parts together, overhanging masonry teeth were inserted along the height, with a spacing of about $1 \mathrm{~m}$ (Fig. 4a). The same technique is still visible also in other buildings nearby, dating back to the same period (Fig. 4b). During the following years, the building was subjected to important differential soil settlements that were measured by means of a topographic survey (Fig. 4c). For this reason, in the Eighties the East wing was retrofitted and separated from the rest of the building through the creation of a static joint (Fig. 5a), formed by two graphite steel layers in contact with each other (Figs. 5b,c), and designed by Prof. Cestelli-Guidi in order to allow vertical relative displacements and block horizontal ones.

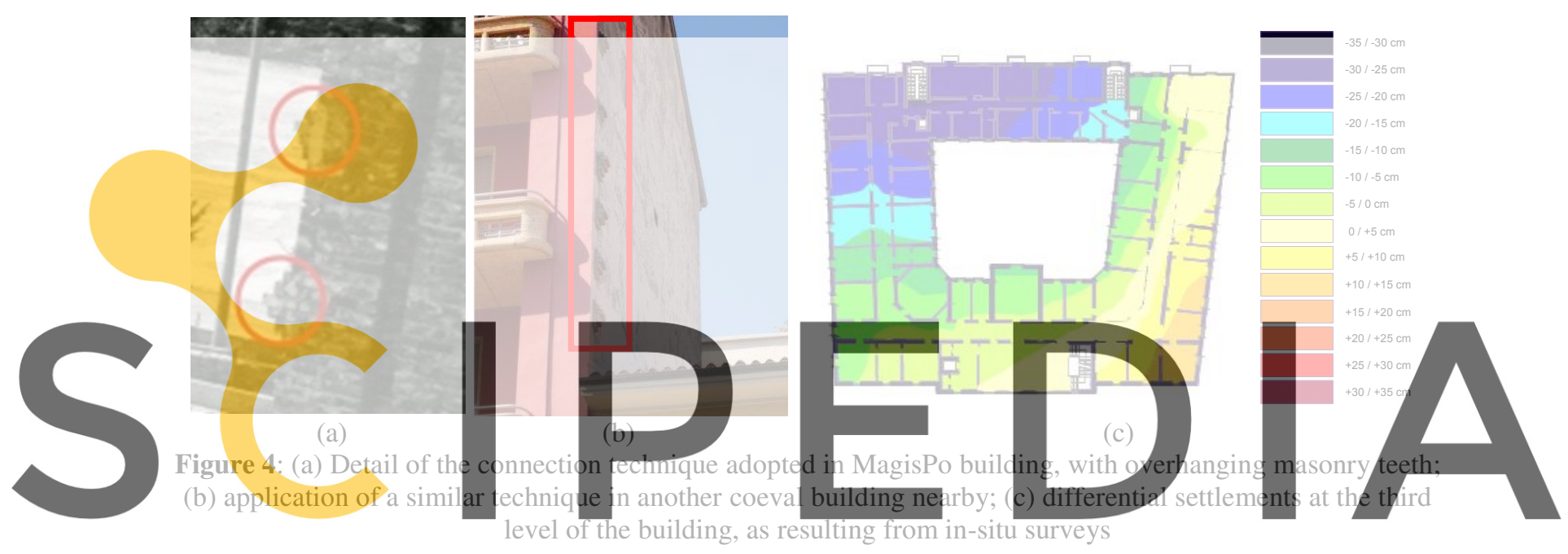

Register for free at http\$//www.scipedia.com to download the version without the watermark

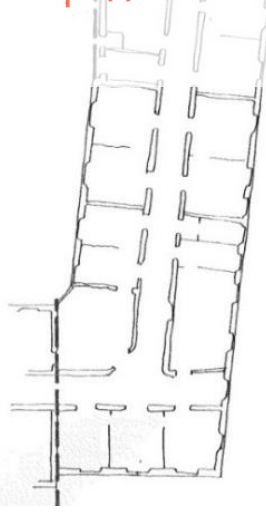

(a)

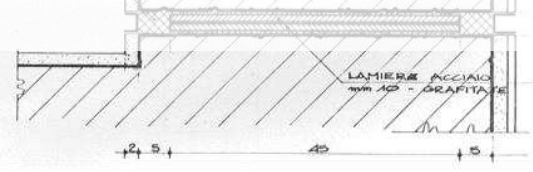

(b)

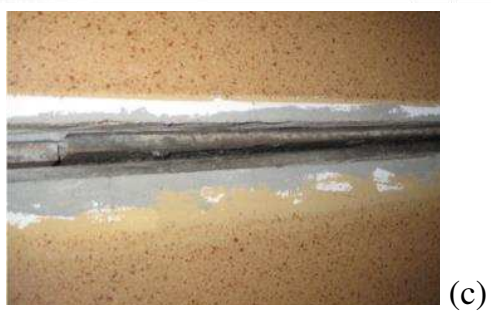

Figure 5: (a) Static joint separating the East wing from the rest of the building; (b) sketch and (c) realization of the joint

Nowadays the structure has a rectangular hollow floor plan, about $56 \mathrm{~m} \times 40 \mathrm{~m}$, with a squared inner court. In elevation, there is an underground floor, four floors above ground, and an attic in the rear portion only, reaching $23 \mathrm{~m}$. The load bearing structure is made of masonry walls in 
The building has a mixed masonry - Reinforced Concrete (RC) structure. Besides the RC columns of the arcade running along the building perimeter at the ground floor (Figs. 6c, 7b), most of the remaining frames are located at the front of the palace at the lower levels, while at the upper ones they are replaced by masonry columns and walls. Between the $3^{\text {rd }}$ and the $4^{\text {th }}$ levels, the floorplan of the building becomes narrower, to allow the realization of a terrace running along the whole perimeter. For this reason, the corresponding floor is characterized by the presence of a grid of RC beams (Fig. 9a), which support the above masonry walls.

Masonry walls are generally constituted by solid bricks and lime mortar, but hollow bricks were also found at the upper levels of the building (see Fig. 10c). Most of the floors are realized with RC joists and interposed hollow clay blocks, with a $50 \mathrm{~mm}$ unreinforced concrete deck. The floor right above the main entrance is instead characterized by a bidirectional grid of RC joists with two layers of interposed hollow clay blocks (Fig. 9b), while the two rooms near the corners of the building, between the ground and the $1^{\text {st }}$ floor, are covered by a lightened slab with radial reinforcement.

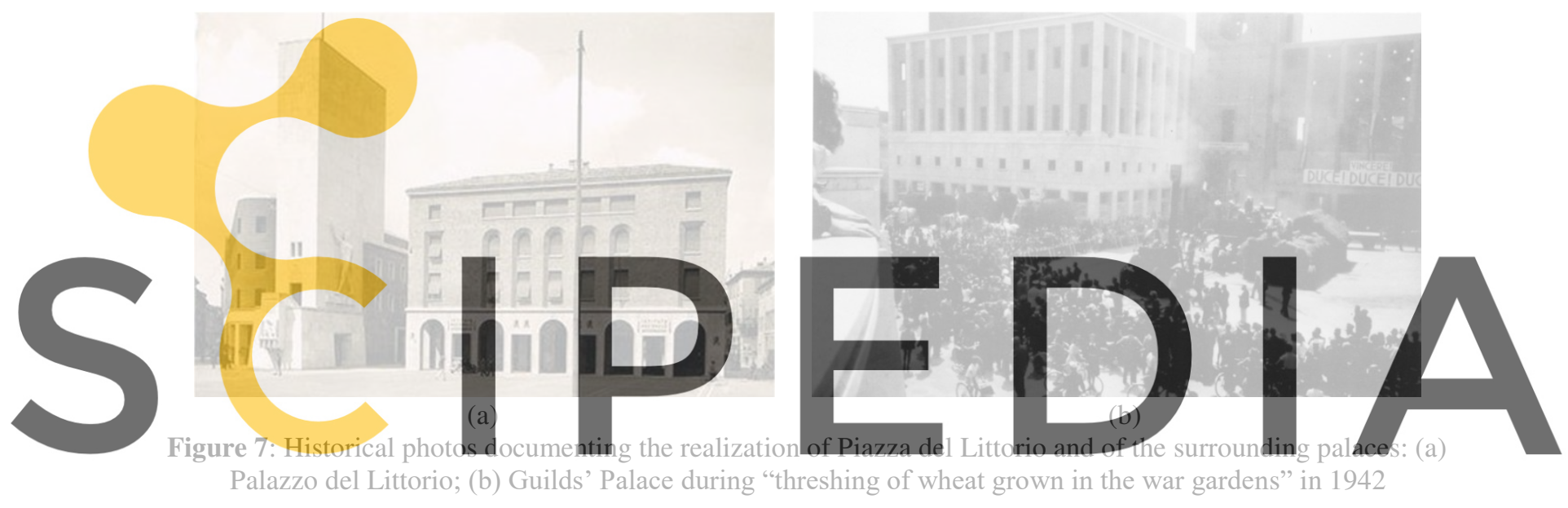

Register for free at https//www.scipedia.com to download the version without the watermark

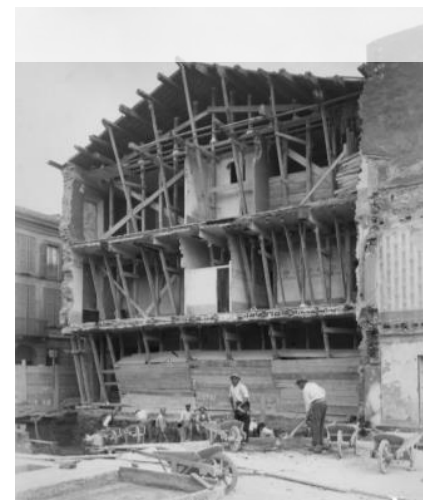

(a)

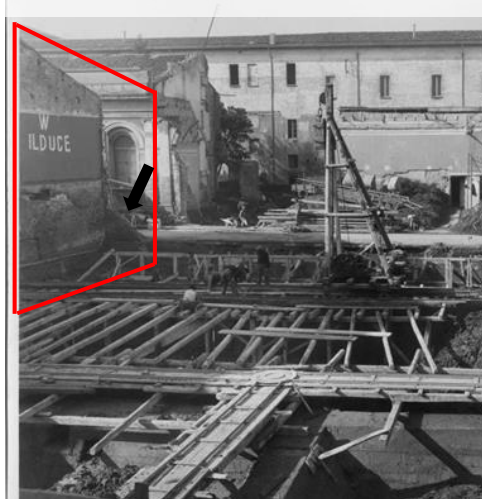

(b)

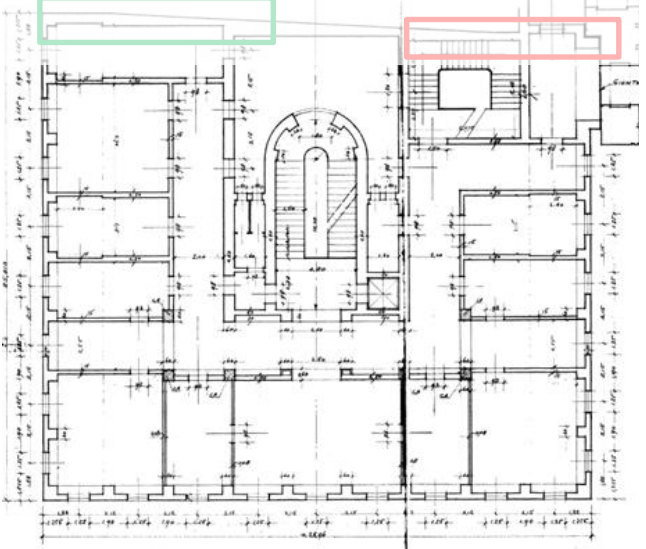

(c)

Figure 8: Historical photos documenting the dismantlement of the aggregate in the late Twenties: (a) demolition of the wall in correspondence of Guilds' Palace West wing (green box in Fig. 8c), (b) wall neighboring with the East wing of the palace (red box in Fig. 8c); (c) floorplan of the building, taken from the draft of Arch. Mongiovì 


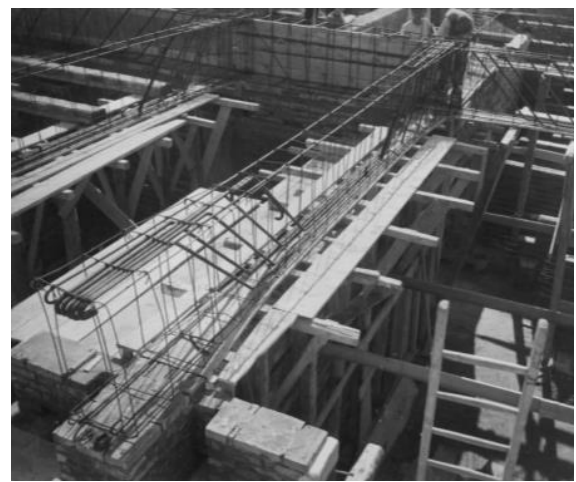

(a)

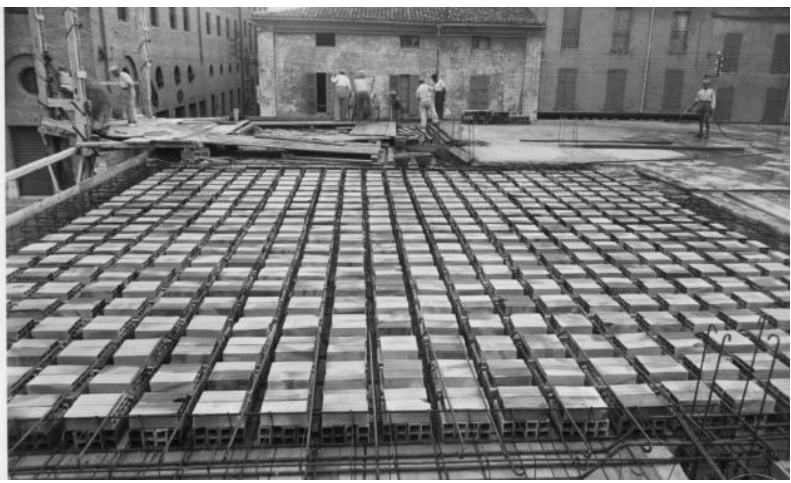

(b)

Figure 9: Historical photos documenting the construction works of the Guilds' Palace: (a) grid of reinforced concrete beams, at the $3^{\text {rd }}$ floor; (b) floor between the ground and the $1^{\text {st }}$ level, with bidirectional concrete joists and interposed hollow clay blocks

\section{IN SITU SURVEYS}

In situ survey encompasses all those activities that allow the identification of the load bearing structure of an existing building, the loads acting on it, and the existence of possible pathologies. The information collected in this knowledge phase, concerning the geometry of the building, the type and dimensions of structural elements, the construction details, the crack pattern, the presence of structural and non-structural vulnerabilities, as well as material properties and

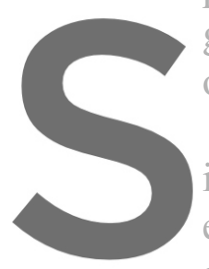
geotechnical aspects, are the bisis for subsequent structural andyses andexert a deep influence
on the related modelling choices.
This Section provides a general overview of performed activities, common to both the
investigated structures, while the following subsections deepen the specific choices related to
each single case study. For the two considered buirdings, a complete geometric and architctural
survey was first performed. Despite the availability of the historical drawings, several

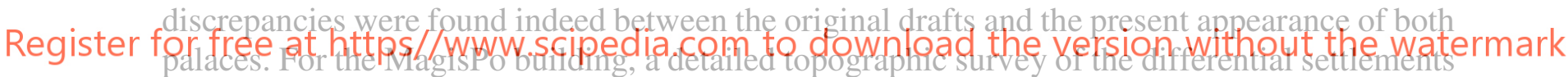

at different floors was also carried out (Fig. 4c), in order to compare it with the one carried out before the retrofit intervention.

Historical documents were a source of valuable information for the identification of the load bearing structure and of the different materials adopted during the construction of both palaces. Available data were analyzed and used for the planning of in situ essays, which were carried out by using both non-destructive and partially destructive techniques. The removal of plaster portions of about $1 \mathrm{~m}^{2}$ (Fig. 10) allowed to identify masonry typology and texture, its possible degradation, the quality of the connections between perpendicular walls and between walls and floors (Fig. 10b,c), as well as the possible presence of concrete joists and lintels above the openings. These essays were distributed at different locations of the floorplan - according to the historical evolution - and were repeated at the different levels, in an extensive and systematic way. The quality of transverse connections within masonry thickness was verified at predefined locations through the removal of single bricks (Fig. 10a,b), which were subsequently delivered to the Laboratory of Materials and Structures of the University of Parma, for the determination of their compressive strength (Fig. 11a,b). During this operation, it was also possible to examine the quality of the mortar and to take a sample for subsequent 
mineralogical and petrographic analyses (Fig. 11c). Wall thickness was verified by means of small drill holes.

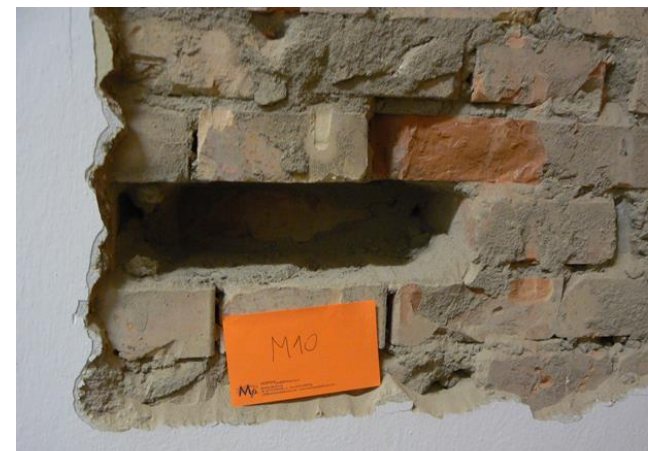

(a)

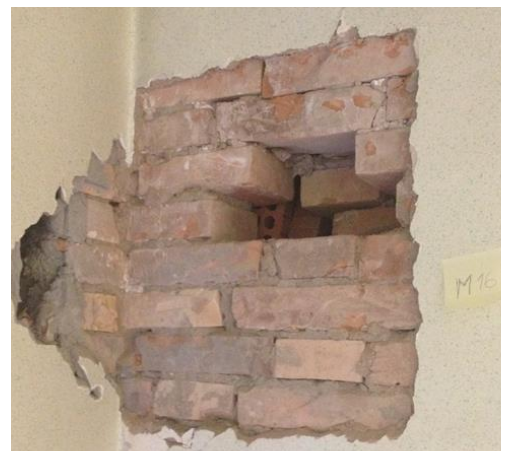

(b)

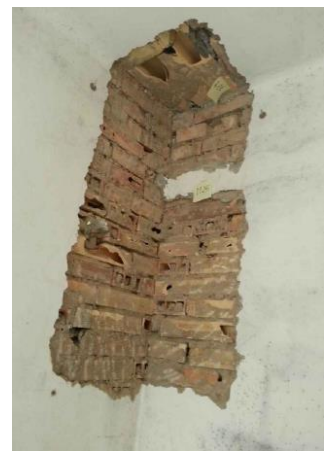

(c)

Figure 10: Removal of plaster portions at different locations of the Guilds' Palace: (a) internal masonry wall at the $1^{\text {st }}$ floor; (b) connection between two perpendicular external walls at the $2^{\text {nd }}$ floor; (c) connection between perpendicular walls and the ceiling at the $5^{\text {th }}$ floor

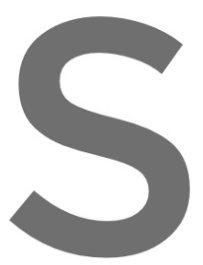

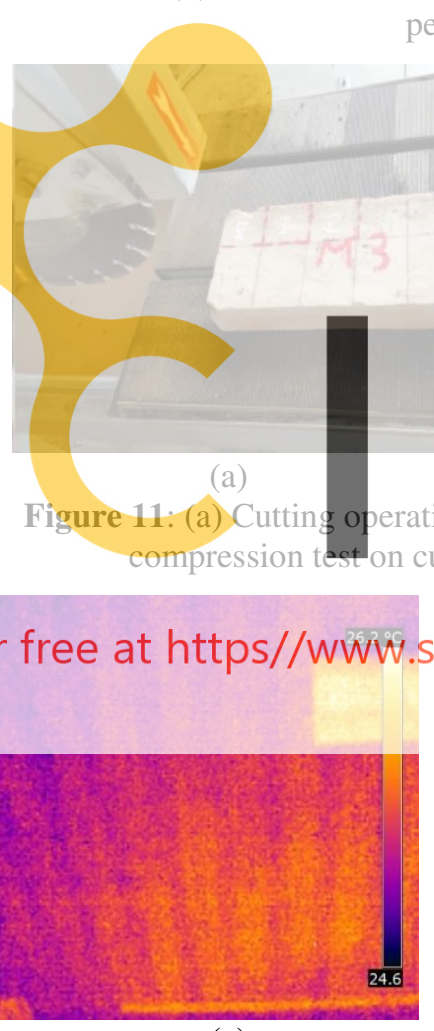

(a)

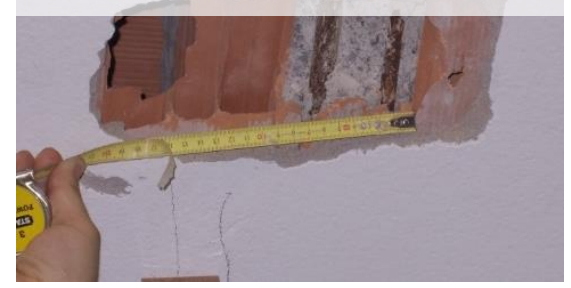

(b)

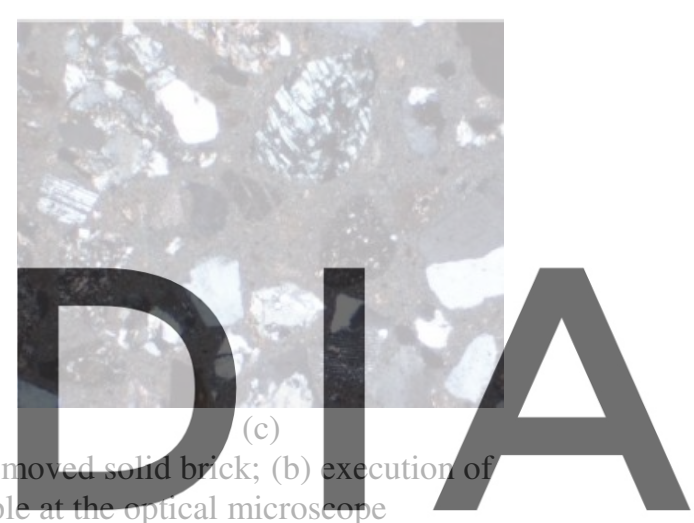

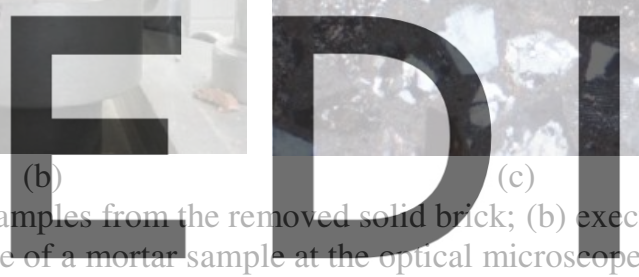

4

Register for free at https//www.scipedia.com to download the version without the watermark

Figure 12: In situ survey on floors: (a) thermographic analysis; (b) removal of plaster layer and concrete cover; (c) core drilling at floor extrados

The direction and typology of floors were checked by means of visual inspections and nondestructive techniques, like thermographic (Fig. 12a) and pacometric analyses, supported by semi-destructive local essays (Fig. 12b), consisting in the removal of plaster layer and concrete cover, and in the measurement of rebar diameters and spacing. Floor stratigraphy was deduced by means of coring at floor extrados (Fig. 12c), while its thickness was measured by performing small drill cores. Similar techniques were also adopted for RC elements (beams, concrete ring 
beams, columns). The information deduced from original historic documents were first verified through a simulated design according to the Code Standard in force at the time. Rebars distribution and diameters were then verified through extensive pacometric investigations, further integrated by local essays requiring the removal of plaster and concrete cover.

\subsection{The "MagisPo" building in Parma}

Since building construction took place in three subsequent phases, in situ survey on masonry was organized so to have a minimum number of essays for each part, and at every level. For each part, plaster was removed to characterize the main masonry typologies, individuated on the basis of their position (internal/external wall) and thickness (from 150 to $550 \mathrm{~mm}$ ). Some essays were also performed in correspondence of the junctions between the different parts, to confirm the presence of overhanging masonry teeth (Figs. 4a, 13a). A specific survey was also planned near the static joint realized in the Eighties, during the retrofitting works. The availability of several photos documenting the construction phases was also useful to identify different materials and construction techniques (i.e. flat arches above the openings in the underground floor and RC lintels at the other levels; presence of lightly reinforced concrete ring beams, the bearing structure of stairs, etc.), which were verified in situ through targeted interventions. A total of 19 essays were carried out for the determination of masonry typology, with the removal of 7 bricks and 11 mortar samples.
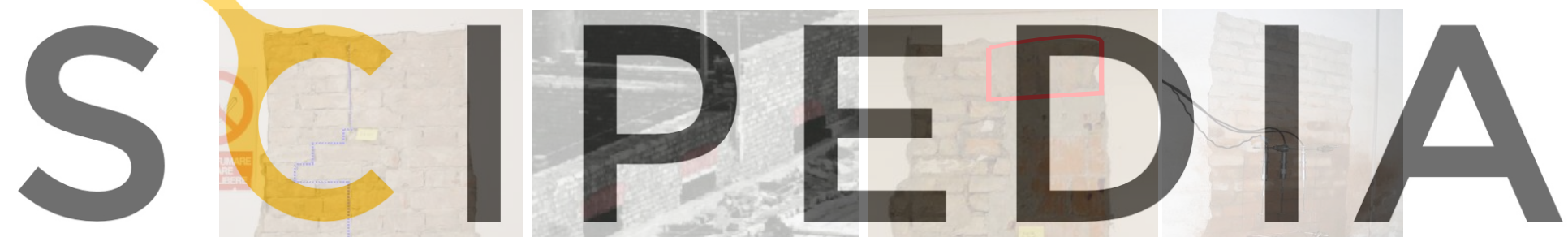

Register for free at https//www.scipedia.com to download the version without the watermark

(a)

(b)

(c)

(d)

Figure 13: In situ survey: (a) connection between two wall portions realized at different times; presence of flat arches above the openings at the underground floor from (b) historical photos and (c) direct essays; (d) double flat jack test on a masonry pier of the underground floor

Compressive tests were carried out on cubes with $50 \mathrm{~mm}$ side obtained from bricks extracted from the building walls (approximately 4 or 5 cubes for each brick, Figs. 11a,b). These tests provided an average strength value of $23 \mathrm{MPa}$. Lower compressive strengths were found for those samples taken from the underground level, where different, lower quality bricks, characterized by a paler color, were used. From laboratory tests, mortar was classified as poor. A masonry pier located at the underground floor was chosen to perform a double flat jack test (Fig. 13d), which provided a masonry compressive strength value of about 2.4 MPa. This value corresponds to the minimum value suggested in the commentary document [8] joined to the current Italian Code [9] for the category "solid brick masonry with lime mortar". Considering an intermediate level of knowledge $[9,10]$ achieved through the in situ survey, and taking into account that the results of the double flat jack test were referred to the masonry with the poorer 
quality in all the building (concentrated at the underground level), the central values of the interval reported in [8] for masonry strengths were adopted. These values were further reduced through the application of the confidence factor, according to the followed Standard Codes $[9,10]$.

\subsection{The Guilds' Palace}

As for the MagisPo building, in situ survey on the Guilds' Palace were planned to verify the reliability of the information collected during the historical research, and to deepen the less clear aspects. In this case, great attention was paid to the investigation of the relations between the studied building and the adjacent ones belonging to the pre-existing aggregate, as well as to the neighboring tower, carrying out visual inspections also in these adjacent structures, to understand better possible interactions, especially during earthquake.

A total of 25 inspections on masonry quality and texture were planned, by examining walls with different position (external/internal) and thicknesses at different levels, and performing a higher number of essays on the wall separating the Guilds' Palace from the aggregate. 14 solid bricks were collected for the determination of material properties through laboratory tests. Compressive tests on cubic samples with $50 \mathrm{~mm}$ side obtained from the bricks provided an average compressive strength of $24.5 \mathrm{MPa}$, but were quite dispersed, even for cubes belonging to the same batch. Lime mortar was characterized by a poor quality. Considering an intermediate level of knowledge $[9,10]$ achieved through the in situ survey, the central values of the interval reported in [8] for the category "solid brick masonry with
lime mortar" were adopted for material strength calculation. These values were further
reduced through the application o the confidence factor, which was in this case
calculated according to the procedtrie suggested in [11] for heritage buildings, as it is in
the examined case. A value of 1.23 , very similar to that suggested in [8] for an internediate knowledge level, was found.

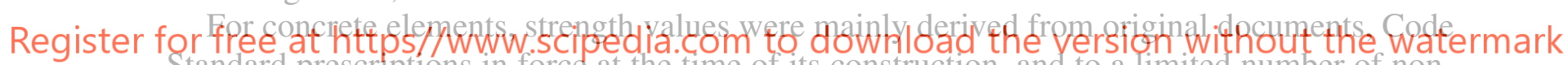
Standard prescriptions in force at the time of its construction, and to a limited number of nondestructive tests. Several semi-destructive essays were originally planned, but their execution was not possible for the negative advice of the Superintendence and of the Property.

\section{VULNERABILITY ASSESSMENT OF THE TWO CONSIDERED BUILDINGS}

The information collected during the knowledge phase were used as basis for the structural modelling. The effectiveness of connections between perpendicular walls and between walls and floors, the presence of concrete ring beams at floor levels, and the lack of important crack patterns denoting clear out-of-plane mechanisms in both the examined palaces, made reasonable the choice of analyzing the behavior of the whole building, by considering a 3D model. In both cases, the underground floor was not included in numerical simulations (Fig. 14a,b). To achieve a good compromise between accuracy of the results and computational effort, an equivalent-frame macro-element approach was adopted [12]. As a first step, linear analyses under gravity load were performed. In this way, it was possible to easily check the accuracy of the geometric layout and of the assumed applied loads, through the comparison between numerical stress values and those deriving from simple manual calculations, as well as from experimental data (i.e. provided by flat jacks). For the vulnerability assessment of the buildings behavior under seismic loads, the nonlinear static (pushover) analysis was chosen, 
since it is currently considered the best-established method for masonry structures, and it is frequently used in case of historical constructions [13, 14]. Based on the available information on the foundation soil, a soil category $\mathrm{C}$ according to $[9,10]$ was assumed in both cases without any topographic amplification.

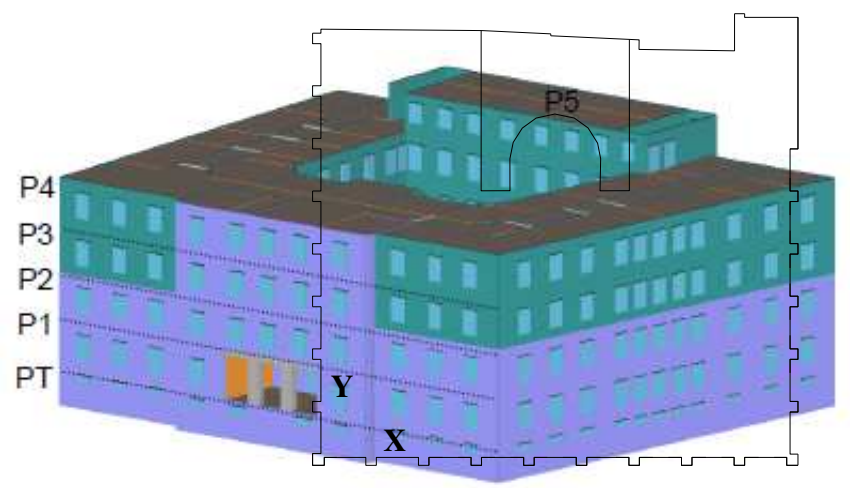

(a)

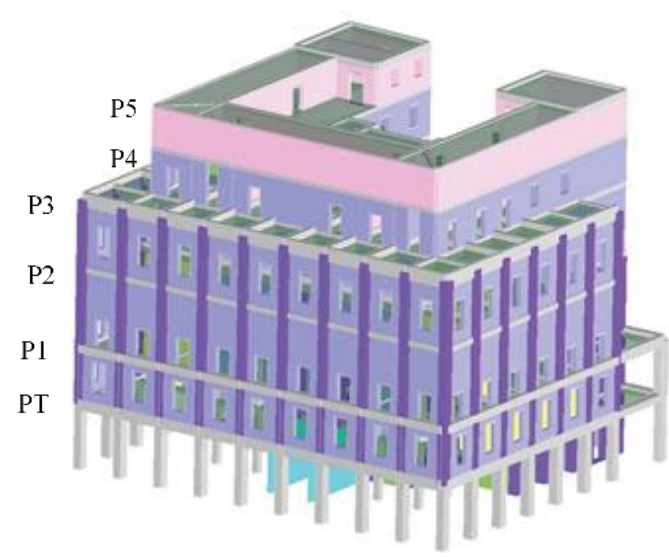

(b)

Figure 14: View of the 3D model adopted for (a) the MagisPo building and (b) the Guilds' Palace

Different models were considered for both the structures examined. Besides a general model of the whole building (Fig. 14), other possible scenarios were investigated, based on the relevant information collected for each case study. For the MagisPo, the behavior of the two portions separated by the joint (realized during the retrofitting intervention dating back to the ' $80 \mathrm{~s}$ ) was also investigated. It was generally found that the weaker direction for the building under seismic action was that parallel to the main façades, for the presence of two RC frames at the ground floor, interrupting the continuity of shearwalls. Another problem highlighted in the analyses was represented by masonry spandrels, which were weakened by the presence of niches hosting the shutters and the heaters. The return period of the maximum seismic action sustainable by the whole building was found to be slightly lower than 350 years, while it was almost halved when considering the building split into two independent portions. However, this latter scenario seems to be less realistic, since documental findings and in situ survey have proved that the joint between the two parts is more effective with regards to vertical loads than horizontal ones.

For the Guilds' Palace, two separate models were analyzed, by including or not a limited portion of the aggregate behind it. In both cases, it was found that the weaker direction for the building under seismic action was that parallel to the main façade, due to the limited number of shearwalls continuous along the building height. As already observed, shearwalls are lacking in the portion of the ground floor near the main entrance, where RC frames were preferred. The return period of the maximum seismic action sustainable by the whole building was found to be approximately equal to 150 years, and this results is only slightly modified when including an aggregate portion.

\section{CONCLUSIONS}

The importance of the knowledge path in order to approach correctly the analysis of an existing structure is a self-evident concept. Less evident is how to carry out this knowledge path on buildings - like the ones dating back to the mid-twentieth century - that are not made like 
present-day structures but are neither traditional buildings with a long and well-studied experience. The two analyzed case studies focus on the methodology for the structural analysis of this type of buildings, highlighting the need of a strict relation between historical research, on-site surveys and numerical analyses. In particular, the identification of construction phases, changes occurred in time, and earlier structural retrofit interventions have proved to be meaningful information for the definition of the bearing schemes of the buildings and, as a consequence, of their numerical models. In case of uncertainties, like for connections effectiveness in aggregate structures, different conditions have been modeled to check their influence on the global behavior, supplying an idea of the possible variability of the results. The final aim is increasing not only theoretical sensitiveness but also technical awareness of the specificities of the structural analysis on modern architecture.

\section{REFERENCES}

[1] Codice dei Beni Culturali, D.L. n.42, 22/91/2004. In G.U.R.I. n.45, 24/2/2004 (in Italian).

[2] Brandi, C., Theory of restoration. Translation by Cynthia Rockwell. Florence: Nardini.

[3] Giuffrè, A., Carocci, C., Statica e dinamica delle costruzioni murarie storiche. In: Proc. CNR Int Congress "Le pietre da costruzione: il tufo calcareo e la pietra leccese", Mario Adda Editore, Bari, (1993): 539-598 (in Italian).

[4] Ceroni, F., Pecce, M., Sica, S. and Garofano, A. Assessment of seismic vulnerability of a historical masonry building. Buildings (2012) 2: 332-358.

[5] Lagomarsino, S., Cattari, S., Degli Abbati, S. and Ottonelli, D. Seismic assessment of complex monumental buildings in aggregate: the case study of Palazzo del Podestà in Mantua (Italy). In: F. Peña et al. (Eds.): SAHC2014-9th international conference on structural analysis of historical constructions, Mexico City, Mexico (2014).

[6] Caprili, S. and Puncello, I. Knowledge-Based Approach for the Structural Assessment of Monumental Buildings: Application to Case Studies. Front. Built Env. (2019) 5: 52.

[7] Boschi, S., Borghini, A., Pintucchi, B. and Zani, N. Seismic vulnerability of historic masonry buildings: A case study in the center of Lucca. Procedia Struct. Integr. (2018) 11: 169-176.

[8] Circolare n. 617. Instructions for the application of "Nuove norme tecniche per le costruzioni di cui al D.M. 14 gennaio 2008", (in Italian), 2009.

[9] NTC 2008. Norme Tecniche per le Costruzioni, D. M. 14/01/2008. In G.U.R.I., 29, $04 / 02 / 2008$ (in Italian).

[10] UNI EN 1998-3. Eurocode 8. Design of structures for Earthquake resistance - Part 3: Assessment and Retrofitting of Buildings (2005).

[11] Guidelines for the assessment and reduction of seismic risk for cultural heritage according to Italian Standard (D.M. 14 Jan 2008), (in Italian), 2011

[12]Penna, A., Lagomarsino, S. and Galasco, A. A nonlinear macro-element model for the seismic analysis of masonry buildings. Earthq Eng Struct Dyn (2014) 43(2):159-179.

[13]Bracchi, S., Rota, M., Penna, A. and Magenes, G. Consideration of modelling uncertainties in the seismic assessment of masonry buildings by equivalent-frame approach. Bull Earthquake Eng (2015) 13: 3423-3448.

[14] Ceroni, F., Pecce, M., Manfredi, G. Modelling and seismic assessment of the bell Tower of Santa Maria del Carmine: Problems and solutions. J. Earthq. Eng. (2010) 14: 30-56. 